Pacific Journal of Mathematics

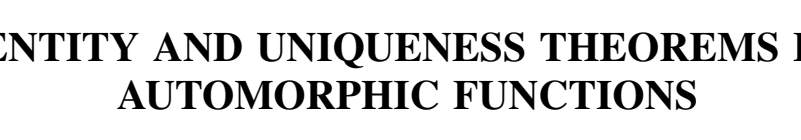




\title{
IDENTITY AND UNIQUENESS THEOREMS FOR AUTOMORPHIC FUNCTIONS
}

\author{
Peter LAPPAN
}

1. Introduction. Let $C$ and $D$ denote the unit circle and the unit disk, respectively, and let $\rho\left(z, z^{\prime}\right)$ denote the non-Euclidean hyperbolic distance between the points $z$ and $z^{\prime}$ in $D$ [3, Chapter II]. Bagemihl and Seidel have proved the following identity theorem [2, Theorem 3, p. 13].

THEOREM A. Let $f(z)$ be a meromorphic function of bounded characteristic in $D$, and let $\left\{z_{n}\right\}$ be a sequence of points in $D$ with at least two limit points in $C$, such that $\left|z_{n}\right| \rightarrow 1$ and $\rho\left(z_{n}, z_{n+1}\right)<M$ for every $n$, where $M$ is a positive constant. If $f\left(z_{n}\right) \rightarrow c$, then $f(z) \equiv c$.

There is also a corresponding uniqueness theorem [2, Theorem 4, p. 14].

THEOREM B. Let $f(z)$ and $g(z)$ be meromorphic functions of bounded characteristic in $D$, and let $\left\{z_{n}\right\}$ be a sequence of points in $D$ with at least two limit points in $C$, such that $\left|z_{n}\right| \rightarrow 1$ and $\rho\left(z_{n}, z_{n+1}\right)<M$ for every $n$, where $M$ is a positive constant. If $\left\{f\left(z_{n}\right)-g\left(z_{n}\right)\right\} \rightarrow 0$, then $f(z) \equiv g(n)$.

Along the same lines, Bagemihl has proved an identity theorem for normal functions [1, Theorem 3, p. 4].

THEOREM C. Let $f(z)$ be a normal meromorphic function and let $\left\{z_{n}\right\}$ be a sequence of points in $D$ with at least two limit points in $C$, such that $\left|z_{n}\right| \rightarrow 1$ and $\rho\left(z_{n}, z_{n+1}\right) \rightarrow 0$. If $f\left(z_{n}\right) \rightarrow c$, then $f(z) \equiv c$.

This paper will investigate such identity and uniqueness theorems for automorphic functions. It shall be shown that there is a result analoguous to Theorem $\mathrm{C}$ for automorphic functions with Fuchsian groups of the first kind. However, an example will show that there is no corresponding theorem for automorphic functions with Fuchsian groups of the second kind. In the case of automorphic functions with

Received November 4, 1963. This paper is a revised version of a portion of the author's doctoral thesis, submitted to the University of Notre Dame in June, 1963. The author wishes to express his thanks to Professor W. Seidel for his help and guidance. This research was supported in part by an NSF grant. 
Fuchsian groups of the first kind, a corresponding uniqueness theorem holds.

2. Some notation and terminology. We begin with some basic definitions about Fuchsian groups and automorphic functions. ${ }^{1}$

DefinITION 1. A group $\mathscr{G}$ of linear transformations of $D$ onto itself is called a Fuchsian group if there exists a point $z_{0} \in D$ and $a$ neighborhood $N\left(z_{0}\right)$ of $z_{0}$ such that $N\left(z_{0}\right) \cap S\left(z_{0}\right)=\phi$ for each $S \in \mathscr{G}$ which is not the identity transformation.

Definition 2. Let $\mathscr{G}$ be a Fuchsian group and let $S(z)=$ $(a z+b) /(c z+d), a d-b c=1, c \neq 0$, be an element of $\mathscr{G}$. The circle $|c z+d|=1$ is called an isometric circle of $\mathscr{G}$, or simply an isometric circle, and is denoted by $I(S)$. The disk $|c z+d| \leqq 1$ is called an isometric disk and is denoted by $K(S)$.

Definition 3. A limit point of the centers of the isometric circles of the transformations of a Fuchsian group $\mathscr{G}$ is called a limit point of $\mathscr{G}$.

DefinITION 4. If every point of $C$ is a limit point of $\mathscr{G}$, then $\mathscr{G}$ is called a Fuchsian group of the first kind. A Fuchsian group which is not of the first kind is said to be of the second kind.

Definition 5. Let $\mathscr{G}$ be a Fuchsian group and let $R_{0}^{\prime}$ be the set of points in $D$ exterior to every isometric disk of $\mathscr{G}$. If $R_{0}$ consists of $R_{0}^{\prime}$ plus a set of boundary points of $R_{0}^{\prime}$ such that every point of $D$ is congruent under $\mathscr{G}$ to exactly one point of $R_{0}$, then $R_{0}$ is called the fundamental region of $\mathscr{G}$.

We note that the fundamental region $R_{0}$ is not unique, but $\bar{R}_{0}$, the closure of $R_{0}$, is unique.

DEFINITION 6. Let $f(z)$ be a meromorphic function in $D$, and let $\mathscr{G}$ be a Fuchsian group. If $f(S(z))=f(z)$ for each $S \in \mathscr{G}$ and each $z \in D$, then $f(z)$ is called an automorphic function.

In addition to the standard terminology, we shall make use of what will be called an $L$-set.

Definition 7. An arcwise connected ${ }^{2}$ subset $A$ of $D$ is called an

1 For a more complete discussion of automorphic functions, the reader is referred to the book by Ford [4].

2 Arcwise connected here means that any two points in $A$ may be jointed be a Jordan arc contained in $A$. 
$L$-set of $D$ if $\bar{A} \cap C \neq \phi$.

3. The main theorems. The proofs of the main results require some preliminary lemmas.

LEMma 1. Let $\mathscr{G}$ be a Fuchsian group, and let $S$ be a nonelliptic transformation in $\mathscr{G}$. Let $B$ be the straight line segment from 0 to $S(0)$, and let $A_{s}=\bigcup_{n=0}^{\infty} S^{n}(B)$. Then $A_{s}$ is an L-set of $D$.

Proof. It is clear that $A_{S}$ is arcwise connected. Since $S$ is nonelliptic, $\left\{S^{n}\right\}$ is an infinite sequence of distinct elements of $\mathscr{G}$, and $\left\{S^{n}(0)\right\}$ may have no limit point in $D$. Hence $A_{s}$ has a limit point in $C$.

In fact, it is easily seen that $A_{s}$ has but a single limit point in $C$. This follows from the geometry of the isometric disks.

LEMMA 2. Let $\mathscr{G}$ be a Fuchsian group of the first kind, and let $\widehat{\alpha \beta}$ be an arc of $C$. Then there exists an L-set $A$ of $D$ whose limit points on $C$ are interior points of $\overparen{\alpha \beta}$ and each point of $A$ is congruent under $\mathscr{G}$ to a point of a compact subset $K$ of $D$.

Proof. It is well known that if a Fuchsian group contains only elliptic elements, then it is is a finite group of the second kind. Let $S$ be any nonelliptic element of $\mathscr{G}$ and let $A_{S}$ be as described in Lemma 1. Let $z_{1}$ be the limit point of $A_{S}$ in $C$. If $z_{1}$ is an interior point of the arc $\widehat{\alpha \beta}$, we set $A=A_{s}$. If $z_{1}$ is not an interior point of $\widehat{\alpha \beta}$, let $z_{2}$ be any interior point of $\widehat{\alpha \beta}$. Let $\left\{T_{n}\right\}$ be a sequence of elements of $\mathscr{G}$ such that $T_{n}(0) \rightarrow z_{2}$. Let $W$ be any element of $\mathscr{G}$ for which $z_{1}$ is not a fixed point. Then either $z_{1}$ or $W\left(z_{1}\right)$ (or perhaps both) is not in infinitely many of the $K\left(T_{n}\right)$ and, by the geometry of isometric circles (see [4, p. 26]), there exists an integer $N$ such that either $T_{N}\left(z_{1}\right)$ or $T_{N}\left(W\left(z_{1}\right)\right)$ is an interior point of $\widehat{\alpha \beta}$. Then we set $A$ equal to the corresponding $T_{N}\left(A_{S}\right)$ or $T_{N}\left(W\left(A_{S}\right)\right)$. Every point of $A$ is congruent under $\mathscr{G}$ to a point of $B$. Setting $K=B$, we see that $A$ is the desired $L$-set.

LEMMA 3. Let $\mathscr{S}$ be a Fuchsian group of the first kind, and let $\widehat{\alpha \beta}$ be an arc of $C$. Let $\left\{z_{n}\right\}$ be a sequence of points in $D$ such that $\rho\left(z_{n}, z_{n+1}\right) \rightarrow 0$ and the set of limit points of $\left\{z_{n}\right\}$ consists of the arc $\overparen{\alpha \beta}$. Let $L$ be the set of limit points of the set $\left\{S\left(z_{m}\right): S \in \mathscr{G}\right.$, $n=1,2,3, \cdots\}$. Then there exists a point of $L$ in $D$.

Proof. By Lemma 2, there exists an $L$-set $A$ of $D$ all of whose points are congruent under $\mathscr{G}$ to points on a compact subset $K$ of $D$, 
and whose limit points in $C$ are interior points of $\overparen{\alpha \beta}$. Since $\rho\left(z_{n}, z_{n+1}\right) \rightarrow 0$, there exists a subsequence $\left\{z_{n_{k}}\right\}$ such that $\rho\left(z_{n_{k}}, A\right) \rightarrow 0$. Then there exist transformations $S_{k} \in \mathscr{G}$ such that $\left\{S_{k}\left(z_{n_{k}}\right)\right\}$ has a limit point $z_{0} \in K$. But $z_{0} \in L$ and $z_{0} \in D$.

LEMMA 4. Let $\mathscr{G}$ be a Fuchsian group of the first kind and let $\widehat{\alpha \beta}$ be an arc of $C$. Let $\left\{z_{n}\right\}$ be a sequence of points in $D$ such that $\rho\left(z_{n}, z_{n+1}\right) \rightarrow 0$ and the set of limit points of $\left\{z_{n}\right\}$ cansists of the arc $\widehat{\alpha \beta}$. Let $L$ be the set of limit points of the set $\left\{S\left(z_{n}\right): S \in \mathscr{G}\right.$, $n=1,2,3, \cdots\}$. Then any point of $L \cap D$ is a limit point of $L$.

Proof. If $z_{0} \in L \cap D$, then there exists a subsequence $\left\{z_{n_{k}}\right\}$ of $\left\{z_{n}\right\}$ and a sequence $\left\{S_{k}\right\}$ of elements of such that $S_{k}\left(z_{n_{k}}\right) \rightarrow z_{0}$. Since $\left\{z_{n}\right\}$ has more than one limit point in $C$, the $n_{k}$ 's can be chosen so that there exists a sequence of integers $\left\{p_{k}\right\}$ such that $p_{k}<n_{k+1}-n_{k}$ and $\rho\left(z_{n_{k}}, z_{n_{k}+p_{k}}\right) \rightarrow \infty$. Let $r>0$ be given. Then for $k$ sufficiently large, we have $\rho\left(z_{0}, S_{k}\left(z_{n_{k}}\right)\right)<r$ and $\rho\left(z_{0}, S_{k}\left(z_{n_{k}+p_{k}}\right)\right)>r$. If, for each $k, q_{k}$ is the least positive integer such that $\rho\left(z_{0}, S_{k}\left(z_{n_{k}+q_{k}}\right)\right)>r$, then $\rho\left(z_{0}, S_{k}\left(z_{n_{k}+q_{k}-1}\right)\right) \leqq r$, and it is easy to see that the sequence $\left\{S_{k}\left(z_{n_{k}+q_{k}}\right)\right\}$ has a limit point $w_{r}$ on the circle $\rho\left(z, z_{0}\right)=r$. Hence $w_{r} \in L$. Thus for each $n$ there exists a point $w_{n} \in L$ such that $\rho\left(w_{n}, z_{0}\right)=1 / n$. This. implies that $w_{n} \rightarrow z_{0}$ and that $z_{0}$ is a limit point of $L \cap D$.

We are now in a position to prove an identity theorem for automorphic functions with Fuchsian groups of the first kind.

IDENTITY THEOREM. Let $\mathscr{G}$ be a Fuchsian group of the first kind and let $f(z)$ be a meromorphic function automorphic with respect to. $\mathscr{G}$. Let $\left\{z_{n}\right\}$ be a sequence of points in $D$ with at least two limit. points on $C$, such that $\left|z_{n}\right| \rightarrow 1$ and $\rho\left(z_{n}, z_{n+1}\right) \rightarrow 0$. If $f\left(z_{n}\right) \rightarrow c$, then. $f(z) \equiv c$.

Proof. Let $L$ be the set of limit points of the set $\left\{S\left(z_{n}\right): S \in \mathscr{G}\right.$, $n=1,2,3, \cdots\}$. By Lemma 3 there exists a point $z_{0} \in L \cap D$, and by Lemma 4 there exists a sequence $\left\{w_{n}\right\}$ of points in $L \cap D$ such that $w_{n} \rightarrow z_{0}$. But $f\left(w_{n}\right)=c$ for each $n$ and $f\left(z_{0}\right)=c$. Therefore, since $f(z)$ assumes the same value on a sequence of points in $D$ with a limit point in $D, f(z) \equiv c$.

Since the sum of two automorphic functions with the same Fuchsian group is itself automorphic, we have a corresponding uniqueness theorem.

UNIQUeness TheOREM. Let $\mathscr{G}$ be a Fuchsian group of the first kind, and let $f(z)$ and $g(z)$ be two meromorphic functions automorphic with respect to $\mathscr{G}$. Let $\left\{z_{n}\right\}$ be a sequence of points in $D$ with at. 
least two limit points on $C$ such that $|z| \rightarrow 1$ and $\rho\left(z_{n}, z_{n+1}\right) \rightarrow 0$. If $\left\{f\left(z_{n}\right)-g\left(z_{n}\right)\right\} \rightarrow 0$, then $f(z) \equiv g(z)$.

4. Groups of the second kind. The identity and uniqueness theorems stated in $\S 3$ are not true if $\mathscr{G}$ is a Fuchsian group of the second kind.

EXAMPLE. There exists a nonconstant meromorphic function $f(z)$ automorphic with respect to a Fuchsian group $\mathscr{G}$ of the second kind, and a set of points $\left\{z_{n}\right\}$ in $D$ with at least two limit points in $C$ such that $\left|z_{n}\right| \rightarrow 1, \rho\left(z_{n}, z_{n+1}\right) \rightarrow 0$, and $f\left(z_{n}\right) \rightarrow 0$.

Proof. Let $\mathscr{G}$ be a Fuchsian group of the second kind. Without loss of generality, we may assume that there exists a number $k$, $0<k<1$, such that the set $\{z: z \in D, \mathscr{R}(z)>1-k\}$ is a subset of $R_{0}$. Let $F$ be the union of the half-plane $\mathscr{R}(z)<1-k / 2$ and $D$. Let $\left\{z_{n}\right\}$ be a sequence of points in $D$ with at least two limit points on $C$ such that $\left|z_{n}\right| \rightarrow 1, \mathscr{R}\left(z_{n}\right)>1-k / 2$, and $\rho\left(z_{n}, z_{n+1}\right) \rightarrow 0$. By a well-known theorem of Mittag-Leffler together with the Riemann Mapping Theorem, there exists a meromorphic function $M(z)$ in $F$ whose only poles are at the points $\left\{z_{n}\right\}$, each pole being of order one. Then $M(z)$ is holomorphic and uniformly bounded in $D-R_{0}$. If the elements of $\mathscr{G}$ are denoted by $\left\{S_{n}\right\}$, where $S_{n}(z)=\left(a_{n} z+b_{n}\right) /\left(c_{n} z+d_{n}\right)$, then for $m \geqq 2$,

$$
H_{1}(z)=\sum_{n=1}^{\infty} M\left(S_{n}(z)\right) \cdot \frac{1}{\left(c_{n} z+d_{n}\right)^{2 m}}
$$

and

$$
H_{2}(z)=\sum_{n=1}^{\infty} \frac{1}{S_{n}(z)} \cdot \frac{1}{\left(c_{n} z+d_{n}\right)^{2 m}}
$$

define meromorphic functions in $D$, and

$$
f(z)=H_{2}(z) / H_{1}(z)
$$

is automorphic with respect to $\mathscr{G}$ (The argument that $H_{1}(z)$ is meromorphic is identical to that of the proof of [4, Theorem 2, p. 105]). Further, for each $n, f\left(z_{n}\right)=0$. But $f(z)$ has a pole at $z=0$, and thus $f(z)$ is nonconstant function.

\section{REFERENCES}

1. F. Bagemihl, Some identity and uniqueness theorems for normal meromorphic functions, Ann. Acad. Sci. Fennicae A. I. 299 (1961) 1-6. 
2. F. Bagemihl and W. Seidel, Sequential and continuous limits of meromorphic functions, Ann. Acad. Sci. Fennicae A. I. 280 (1960), 1-17.

3. C. Carathéodory, Conformal representation, Second Edition, Cambridge, 1952.

4. L. R. Ford, Automorphic functions, Second Edition, New York, 1951.

\section{LEHIGH UNIVERSITY}




\title{
PACIFIC JOURNAL OF MATHEMATICS
}

\author{
EDITORS
}

\author{
RoBerit OsSERman \\ Stanford University \\ Stanford, California
University of Washington
Seattle 5 , Washington \\ M. G. Arsove
}

\author{
J. DugundjI \\ University of Southern California
}

Los Angeles 7, California

Lowell J. Paige

University of California

Los Angeles 24, California

\section{ASSOCIATE EDITORS}
E. F. BECKENBACH
B. H. NeumanN
F. WOLF
K. YOSIDA

\section{SUPPORTING INSTITUTIONS}

\author{
UNIVERSITY OF BRITISH COLUMBIA \\ CALIFORNIA INSTITUTE OF TECHNOLOGY \\ UNIVERSITY OF CALIFORNIA \\ MONTANA STATE UNIVERSITY \\ UNIVERSITY OF NEVADA \\ NEW MEXICO STATE UNIVERSITY \\ OREGON STATE UNIVERSITY \\ UNIVERSITY OF OREGON \\ OSAKA UNIVERSITY \\ UNIVERSITY OF SOUTHERN CALIFORNIA
}

\author{
STANFORD UNIVERSITY \\ UNIVERSITY OF TOKYO \\ UNIVERSITY OF UTAH \\ WASHINGTON STATE UNIVERSITY \\ UNIVERSITY OF WASHINGTON \\ * * * * \\ AMERICAN MATHEMATICAL SOCIETY \\ CALIFORNIA RESEARCH CORPORATION \\ SPACE TECHNOLOGY LABORATORIES \\ NAVAL ORDNANCE TEST STATION
}

Mathematical papers intended for publication in the Pacific Journal of Mathematics should by typewritten (double spaced), and on submission, must be accompanied by a separate author's résumé. Manuscripts may be sent to any one of the four editors. All other communications to the editors should be addressed to the managing editor, L. J. Paige at the University of California, Los Angeles 24, California.

50 reprints per author of each article are furnished free of charge; additional copies may be obtained at cost in multiples of 50 .

The Pacific Journal of Mathematics is published quarterly, in March, June, September, and December. Effective with Volume 13 the price per volume (4 numbers) is $\$ 18.00$; single issues, $\$ 5.00$. Special price for current issues to individual faculty members of supporting institutions and to individual members of the American Mathematical Society: $\$ 8.00$ per volume; single issues $\$ 2.50$. Back numbers are available.

Subscriptions, orders for back numbers, and changes of address should be sent to Pacific Journal of Mathematics, 103 Highland Boulevard, Berkeley 8, California.

Printed at Kokusai Bunken Insatsusha (International Academic Printing Co., Ltd.), No. 6, 2-chome, Fujimi-cho, Chiyoda-ku, Tokyo, Japan.

PUBLISHED BY PACIFIC JOURNAL OF MATHEMATICS, A NON-PROFIT CORPORATION

The Supporting Institutions listed above contribute to the cost of publication of this Journal. but they are not owners or publishers and have no responsibility for its content or policies. 


\section{Pacific Journal of Mathematics}

\section{Vol. 14, No. $4 \quad$ August, 1964}

Homer Franklin Bechtell, Jr., Pseudo-Frattini subgroups . . . . . . . . . . . . . . . . 1129

Thomas Kelman Boehme and Andrew Michael Bruckner, Functions with convex means .............................................. 1137

Lutz Bungart, Boundary kernel functions for domains on complex manifolds . . . . . 1151

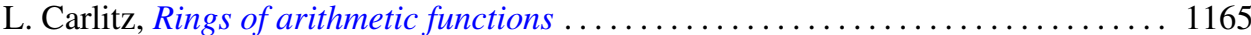

D. S. Carter, Uniqueness of a class of steady plane gravity flows . . . . . . . . . 1173

Richard Albert Dean and Robert Harvey Oehmke, Idempotent semigroups with

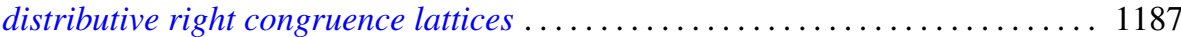

Lester Eli Dubins and David Amiel Freedman, Measurable sets of measures ..... . 1211

Robert Pertsch Gilbert, On class of elliptic partial differential equations in four

variables.......................................... 1223

Harry Gonshor, On abstract affine near-rings .................... 1237

Edward Everett Grace, Cut points in totally non-semi-locally-connected

continua ........................................... 1241

Edward Everett Grace, On local properties and $G_{\delta}$ sets ................ 1245

Keith A. Hardie, A proof of the Nakaoka-Toda formula . . . . . . . . . . . . . . . . 1249

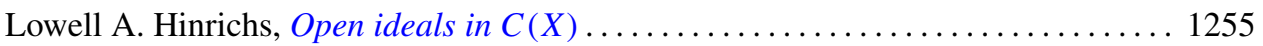

John Rolfe Isbell, Natural sums and abelianizing . . . . . . . . . . . . . . . . 1265

G. W. Kimble, A characterization of extremals for general multiple integral

problems............................................. 1283

Nand Kishore, A representation of the Bernoulli number $B_{n} \ldots \ldots \ldots \ldots \ldots \ldots \ldots \ldots$

Melven Robert Krom, A decision procedure for a class of formulas of first order predicate calculus.

Peter A. Lappan, Identity and uniqueness theorems for automorphic functions ...

Lorraine Doris Lavallee, Mosaics of metric continua and of quasi-Peano spaces . .

Mark Mahowald, On the normal bundle of a manifold..........

J. D. McKnight, Kleene quotient theorems

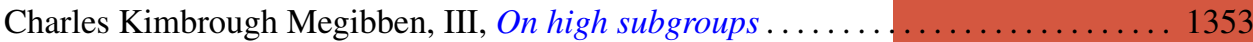

Philip Miles, Derivations on $B^{*}$ algebras . . . . . . . . . . . . . . . . . . . 1359

J. Marshall Osborn, A generalization of power-associativity . . . . . . . . . . . 1367

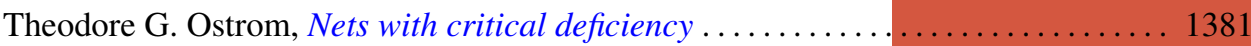

Elvira Rapaport Strasser, On the defining relations of a free product . . . . . . . . . 1389

K. Rogers, A note on orthoganal Latin squares . . . . . . . . . . . . . . . . . . 1395

P. P. Saworotnow, On continuity of multiplication in a complemented algebra ..... 1399

Johanan Schonheim, On coverings . . . . . . . . . . . . . . . . . . . . 1405

Victor Lenard Shapiro, Bounded generalized analytic functions on the torus . . . . . 1413

James D. Stafney, Arens multiplication and convolution . . . . . . . . . . . . . 1423

Daniel Sterling, Coverings of algebraic groups and Lie algebras of classical

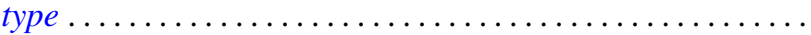

Alfred B. Willcox, Šlov type $C$ algebras over a connected locally compact abelian

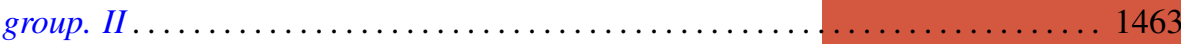

Bertram Yood, Faithful ${ }^{*}$-representations of normed algebras. II . . . . . . . . . 1475

Alexander Zabrodsky, Covering spaces of paracompact spaces 